\title{
Interleukin 12: A Potential Link between Nerve Cells and the Immune Response in Inflammatory Disorders
}

\author{
Laurence A. Turka,* Richard E. Goodman,* \\ J. Lynn Rutkowski, ${ }^{\dagger}$ Anders A.F. Sima, ${ }^{* \neq}$ Andrew Merry, ${ }^{\neq}$ \\ Raj S. Mitra, ${ }^{\ddagger}$ Tamara Wrone-Smith, ${ }^{\ddagger}$ Galen Toews,* \\ Robert M. Strieter, * and Brian J. Nickoloff ${ }^{\ddagger}$ \\ Departments of ${ }^{\star}$ Internal Medicine, ${ }^{\dagger}$ Pediatrics, and ${ }^{\ddagger}$ Pathology, \\ University of Michigan Medical School, Ann Arbor, Michigan, U.S.A.
}

\begin{abstract}
Background: The nervous system has been implicated in several inflammatory skin disorders based on evidence such as the role of stress in inducing lesions, symmetry of lesions, and sparing of denervated skin. Interleukin 12 (IL-12) is a cytokine recently shown to promote cellular immune responses characterized by delayed-type hypersensitivity and production of the THl-lymphokine, interferon- $\gamma$.

Materials and Methods: Using immunohistochemistry, IL-12 immunoreactivity was identified in cryostat sections of normal and diseased human skin samples, and in the peripheral and central nervous system of rodents and human tissue samples. IL-12 p35 and p40 mRNAs were detected using reverse transcriptase-polymerase chain reaction in tissue samples and cultured cells. IL- 12 protein levels were also examined by ELISA and quantitative bioassay utilizing an IL-12-dependent cell line.
\end{abstract}

Results: By immunostaining IL-12 was detected in free nerve ending in the epidermis of normal and diseased skin samples, and also in the dermal nerve fibers. Strong reactivity was detected in axonal processes and in various glial cell types. In addition, IL- 12 protein and mRNA were contained within cutaneous peripheral nerves and spinal cord tissues, and functional levels of IL-12 were produced by cultured Schwann cells.

Conclusions: It is likely that IL-12 is important in initiating or propagating selected inflammatory skin lesions and in determining the pattern of disease that will develop. The presence of IL-12 in neural tissue suggests a mechanism whereby the nervous system can modify or amplify cutaneous and perhaps other immune responses.

\section{INTRODUCTION}

Substantial evidence indicates a cellular and molecular basis for communication between the nervous system and the immune system (reviewed in Ref. 1). In the case of the skin, psoriasis is an autoimmune $\mathrm{T}$ cell-mediated disorder characterized by exacerbation in response to stress and displays a striking symmetry in the distribution of lesions which is similar to patterns of innervation (2). Compounds of neural origin

Address correspondence and reprint requests to: Brian J. Nickoloff, Department of Pathology, University of Michigan, M4232 Medical Science I, 1301 Catherine Street, Ann Arbor, MI 48109-0602, U.S.A. such as substance $\mathrm{P}$ and calcitonin-gene related protein (CGRP) have been localized to skin lesions and implicated in the pathogenesis of this disease (3-5). Interleukin 12 (IL-12), a cytokine produced by antigen-presenting cells, has pleiotrophic effects on natural killer (NK) and T cells, including enhancement of cytotoxicity and interferon- $\gamma($ IFN $\gamma$ ) production (6). In vivo and in vitro, IL- 12 supports the generation of a TH- 1 immune response characterized by cell-mediated immunity and delayed-type hypersensitivity (7).

We were initially interested in examining IL- 12 expression in psoriasis, since this disorder is characterized by a cellular immune reaction featuring TH-1 type lymphocytes (8). Here we 
report that IL-12 is contained within peripheral nerves, including cutaneous sensory nerve endings in the upper dermis and epidermis of normal and diseased skin samples. In addition, IL-12 immunoreactivity was observed in neuronal cells of dorsal root and sympathetic ganglion, the surrounding satellite cells, in peripheral nerve axonal processes and Schwann cells of the sciatic, femoral, and sural nerves, and within oligodendroglial cells of the spinal cord. IL-12 was not identified in anterior horn cells. Identical immunostaining profiles were obtained with different anti-IL- 12 antibodies in both human and rodent tissue samples. Using reverse transcription-polymerase chain reaction (RT-PCR) to detect the inducible-p40 (heavy chain) mRNA of IL-12, transcripts were detected in various rodent tissues including skin, sympathetic ganglion, sciatic and sural nerves, and spinal cord. Examination of purified cell types in culture revealed $\mathrm{p} 40$ mRNA production in oligodendroglial cells, microglial cells, and Schwann cells, but not neuronal cells, astrocytes, or fibroblasts. IL-12 released from these neural cell types needs to be considered as additional non-bone marrow-derived sources of IL-12, and may be important in local inflammatory and immunological responses initiated through exogenous or endogenous neural stimulation.

\section{MATERIALS AND METHODS}

\section{Tissue Samples}

Punch biopsies of human skin were obtained either from normal, healthy individuals $(n=5)$ or from untreated lesions of patients with various dermatological disorders including psoriasis $(n=5)$, challenge phase of allergic contact dermatitis (rhus dermatitis; $n=4$ ), cutaneous $\mathrm{T}$ cell lymphoma (CTCL; $n=4$ ). All biopsies were performed after informed consent and approval of the Human Subjects Committee. Samples of human sural nerve, femoral nerve, and spinal cord $(n=3)$ were obtained from autopsy material within $2 \mathrm{hr}$ of death. Rodent tissue used for all experiments except splenocytes in this study included neonatal and adult BB-Wistar rats, and consisted of foot pad skin, sural and sciatic nerves, dorsal and sympathetic ganglion cells, spinal cord, and brain. Tissue samples were immediately snap frozen in isopentane chilled by liquid nitrogen and stored at $-80^{\circ} \mathrm{C}$.

\section{Tissue Culture}

SCHWANN CELLS: Sciatic nerves dissected from neonatal rat pups were dissociated with trypsin, and the single cell suspension was plated in Dulbecco's modified Eagle's medium (DMEM) supplemented with $10 \%$ heat-inactivated fetal bovine serum (FBS; Sigma Chemical Co., St. Louis, MO, U.S.A.). Fibroblasts were eliminated with an antimitotic and by complement-mediated lysis (9). The Schwann cell population was expanded with $2 \mathrm{mM}$ forskolin and $5 \mu \mathrm{g} / \mathrm{ml}$ of glial growth factor purified from bovine pituitary glands by carboxymethylcellulose chromatography (9). Schwann cells were used after four to five passages and small glass coverslips $(12 \mathrm{~mm}$ in diameter) included in the culture dishes to assess the purity of the cell population by indirect immunofluorescence staining as previously described (10). Schwann cell cultures contained less than $1 \%$ contaminating fibroblasts as identified with antibodies to Thy 1.1 (hybridoma T11D7e2; American Type Culture Collection, Rockville, MD, U.S.A.). Mitogens were removed from the medium at least 5 days before treatment or harvest.

Conditioned medium was collected from rat Schwann cells which were seeded at a density of $10^{6}$ cells $/ 10-\mathrm{cm}$ dish. The feeding medium was replaced with $5 \mathrm{ml}$ of serum-free N2 medium (Gibco-BRL, Gaitherburg, MD, U.S.A.) after 24 $\mathrm{hr}$, and the conditioned medium was collected $48 \mathrm{hr}$ later. After centrifugation at $3,000 \times g$ for $5 \mathrm{~min}$ at $4^{\circ} \mathrm{C}$ to remove debris, aliqouts were stored at $-80^{\circ} \mathrm{C}$ until analysis.

FIBROBLASTS: Perineurial fibroblasts were purified from neonatal rat sciatic nerves by serial subculture in DMEM containing 20\% FBS. Pure cultures were obtained after four passages, and the serum concentration was reduced to $10 \% 1$ week before harvest. Absence of Schwann cell was confirmed by indirect immunofluorescence for S-100 (Dakopatt, Carpinteria, CA, U.S.A.).

DORSAL ROOT GANGLIA NEURONS: Ganglia were dissected from 15-day-old rat embryos, dissociated in $0.25 \%$ acetylated trypsin, and seeded onto 10 $\mathrm{g} / \mathrm{ml}$ of poly-L-lysine coated with plastic dishes. Neurons were maintained in Eagle's minimum essential medium (MEM) with $1.32 \mathrm{~g} / \mathrm{l}$ glucose, $10 \%$ human placental serum, and $50 \mathrm{ng} / \mathrm{ml} 2.5 \mathrm{~S}$ nerve growth factor (Collaborative Research), while contaminating Schwann cells and fibroblasts were removed by two to three cycles of 
antimitotic treatment with $2 \mathrm{mM}$ fluorodeoxyuridine (11). Cultures were grown in serumfree N2 medium containing NGF for 14 days to allow extensive neurite outgrowth. The presence of contaminating cells was apparent by phase contrast microscopy without immunostaining, and cultures containing $>98 \%$ neurons were used in these experiments.

ASTROCYTES, MICROGLIAL, AND OLIGODENDROCYTES: Cerebellar regions dissected from neonatal rat brains were digested in $0.25 \%$ acetylated trypsin, and the cell suspension was seeded into $75-\mathrm{mm}$ culture flasks. Mixed glial cultures were grown to confluence (10-14 days) in DMEM with 10\% FBS, and the various cell types were separated as previously described (11). Cultures enriched in microglia were obtained by shaking the flasks at $260 \mathrm{rpm}$ for $1.5 \mathrm{hrs}$ at $37^{\circ} \mathrm{C}$ and replating the cells in $6-\mathrm{cm}$ plastic dishes. When cultures were harvested 7 days later, astrocytes were the major contaminating cells (approximately 10\%) as determined by indirect immunofluorescent staining with monoclonal antibodies to glial fibrillary acidic protein (GFAP; Boehringer-Mannheim, Indianapolis, IN, U.S.A.).

To obtain oligodendrocytes, fresh medium was added to the flasks and the shaking was continued for $18 \mathrm{hr}$. The detached cells were preplated on plastic for $20 \mathrm{~min}$ and the nonadherent cells were seeded onto poly-lysine-coated dishes. The growth medium was replaced $24 \mathrm{hr}$ later with $\mathrm{N} 2$ medium containing $0.5 \%$ FBS to promote oligodendrocyte differentiation, and the cultures were maintained for 18-21 days. The cultures contained $\geq 70 \%$ oligodendrocytes at harvest, which were identified by staining with anti-galactocerebroside antibodies (Advanced Immunochemicals, Los Angeles, CA, U.S.A.). Nearly all of the contaminating cells were GFAPpositive astrocytes.

The cells remaining in the flask after two successive shake-offs were replated and grown for 7 days in DMEM with 10\% FBS. These cultures contained $\geq 94 \%$ astrocytes as determined by GFAP immunoreactivity.

\section{Immunostaining}

Cryostat sections of skin and nervous tissue $4 \mu \mathrm{m}$ thick underwent immunohistochemical staining using a highly sensitive avidin-biotin peroxidase technique (Vectastain Kit, Vector Laboratory, Burlingame, CA, U.S.A.) as previously described (5). After immunostaining, tissue sections were incubated with the chromogen 3 amino-4-ethyl carbazole (Aldrich Chemical Co., Milwaukee, WI, U.S.A.) producing a positive red reaction product, and counterstained with hematoxylin prior to coverslipping.

The anti-human IL-12 monoclonal antibody (mAb) was a murine IgGl mAb $(12 \mathrm{Hl} / 8.2 .1)$ raised against recombinant human IL-12 (obtained from Stanley F. Wolf, Genetics Institute, Cambridge, MA, U.S.A.). This mAb has been well characterized and immunoprecipitates the p40 and p70 components chains of IL-12. Specificity for staining included the usage of an irrelevant pool of murine IgGl Abs (Coulter Corp, Hialeah, FL, U.S.A.). All Abs were used at a final concentration of $10 \mu \mathrm{g} / \mathrm{ml}$. To verify $A b$ specificity, blocking studies were performed in which the anti-IL-12 Ab solution was preincubated with excess recombinant human IL-12 (gift of S. Wolf) for $24 \mathrm{hr}$ at $4^{\circ} \mathrm{C}$ prior to staining. This preincubation with excess antigen completely abrogated all immunoreactivity for detection of human IL- 12 within both skin and nervous system tissues. Rat tissue samples were immunostained using a sheep anti-murine antibody (G28A,PB2-obtained from Dr. S. Wolf) raised against murine IL-12 p40 chain. The staining procedures used for rat tissues were identical to those used for human tissues. Controls were obtained by omitting the first and/or second antibody and were all negative.

\section{Rat IL-12 p40 Partial cDNA Clone}

Total RNA was isolated by the method of Chomczynski and Sacchi (12): The whole spleen from a Fisher rat was minced and the red blood cells lysed by brief suspension in distilled water. The splenocytes were resuspended at $2 \times 10^{6}$ cells $/ \mathrm{ml}$ and were stimulated for $24 \mathrm{hr}$ in ConA (Sigma) at $S \mu \mathrm{g} / \mathrm{ml}$ in RPMI containing $10 \%$ FBS $>$ Con A-stimulated splenocytes of a Fisher rat. An 821-bp cDNA fragment of rat IL-12 p40 was synthesized from the RNA using MMLV reverse transcriptase and an oligo-dT primer at $42^{\circ} \mathrm{C}$ followed by PCR with Taq polymerase (BoehringerMannheim Biochemicals) as described (13), using redundant mouse/human IL-12 p40 primers specific for a conserved region of the molecule sense primers contain the probable initiation codon at position 17, the antisense primer includes the codon for amino acid 268 of the mouse protein. Purified cDNA fragments were cloned and sequenced. The nucleic acid sequence shares $94 \%$ identity with the corresponding seg- 
ment of the mouse IL-12 p40 mRNA (14) and the translated product shares $92 \%$ identity with the same region of the mouse protein. The rat sequence has been deposited in GenBank under accession number U16674. Primers for use in the RT-PCR analysis for both rat and mouse IL-12 p40 were designed from identical regions of this sequence and span a region of 484 bases internal to the cloning primers.

\section{RT-PCR}

Purified RNA was dissolved in sterile $\mathrm{dH}_{2} \mathrm{O}$ and the concentration adjusted based on the O.D. $260 \mathrm{~nm}$. Bulk RT reactions were performed with each sample/dilution of RNA using oligo-dT (18 mer) and MMLV reverse transcriptase (GibcoBRL), at $42^{\circ} \mathrm{C}$ for $45 \mathrm{~min}$ (13). PCR reactions were performed as described (13), using specific primers for actin (15), mouse IL-12 p35 (16), rat or mouse IL-12 p40 (sense $5^{\prime}$-tggagtcataggctct gga, antisense 5 '-gatgaagaagctggtgctg, product $484 \mathrm{bp}$ ), human IL-12 p35, and human IL-12 p40 (17). PCR was done using an initial denaturation step of $94^{\circ} \mathrm{C}$ for $5^{\prime}$, and temperature cycling of $93^{\circ} \mathrm{C}$ for $45 \mathrm{sec}, 52^{\circ} \mathrm{C}$ for $45 \mathrm{sec}$ and $72^{\circ} \mathrm{C}$ for $80 \mathrm{sec}$ plus $1 \mathrm{sec} / \mathrm{cycle}$. PCR was performed for 25 cycles for $\alpha$-actin or 38 cycles for IL-12 p35 and IL-12 p40, following which $8 \mathrm{ml}$ samples of each product were electrophoresed in agarose gels, blotted on nylon membranes, and UV-crosslinked as described (15). Membranes were hybrized with ddUTP-digoxigenin $3^{\prime}$ endlabeled specific oligonucleotide probe (actin $5^{\prime}$ ggtcaggatgcctctcttg, mouse IL-12 p35 5'-ctagtagc caggcaactc, rat/mouse IL-12 p40 or human IL-12 probes as described (17), then with anti-digoxigenin-alkaline phosphatase, (Boehringer-Mannheim Biochemicals) before incubation with chemiluminescentsubstrate (Lumigen PPD, Boehringer-Mannheim Biochemicals). Hybridized membranes were exposed to X-ray film (Fuji, Inc.) for varied times. Images were recorded with a video camera, with no enhancement.

\section{IL-12 ELISA}

To determine the presence and amount of IL-12 in the tissue samples, frozen samples were thawed with a PBS containing a cocktail of protease inhibitors including $2 \mathrm{mM}$ phenylmethylsulfonylfluoride, $1 \mu \mathrm{g} / \mathrm{ml}$ each of antipan, aprotinin, leupeptin, and pepstatin A, and homogenized, sonicated, and centrifuged at 30,000 $\times g$. The aqueous extracts were filtered through
1.2- $\mu \mathrm{m}$ filters (Gelman Sciences, Ann Arbor, MI, U.S.A.) and analyzed using a specific IL-12 ELISA quantitated by a double ligand method as previously described (16). The Ab used in this procedure was a goat anti-human recombinant IL-12 neutralizing Ab ( $\mathrm{R}+\mathrm{D}$ Systems, Minneapolis, MN, U.S.A.).

\section{IL-12 Bioassay}

To detect functional IL-12 production, rat Schwann cell conditioned medium was analyzed using a bioassay system as previously described (18), except a different IL-12-dependent cell line was used (KIT 225/K6) as described (19).

\section{RESULTS}

\section{IL-12 Immunostaining of Normal and Diseased Human Skin}

In all normal skin samples, there was easily recognizable IL-12 immunostaining of the nerves, both as individual free nerve fibers in the papillary dermis (Fig. 1, arrows), and within nerves that penetrated the basement membrane zone to reach the epidermal compartment (Fig. 1, inset, arrowhead), as well as in larger aggregates of nerve bundles in the mid and deeper dermis (data not shown). Nerve fibers within the pili erector smooth muscle structures could also be visualized as transversing between muscle fibers in a spiraling fashion (Fig. 2). Occasional areas of epidermal keratinocyte staining for IL-12 was observed, but this was not as consistent or as intense as the staining of the nerve fibers. This keratinocyte staining was judged to be nonspecific since in our previous report p40 IL-12 mRNA could not be detected under any culture condition for human keratinocytes (17). An irrelevant IgG cocktail of abs served as another control, and produced no positive staining of any cell types in the skin samples except occasional keratinocyte faint staining (data not shown). IL-12 immunoreactivity in the samples of various skin diseases was similar to the normal skin biopsies with respect to the nerve fibers. In addition to the consistent IL-12 staining of nerve fibers, vascular endothelial cells and occasional dendritic cells in the dermis and epidermis displayed IL-12 immunoreactivity (data not shown).

\section{IL-12 Immunostaining of Normal Rat Skin}

Positive staining for IL-12 was observed in axons contained in small nerve fascicles of the dermis, 
as well as in the free nerve endings and plexa surrounding sweat glands and in juxtaposition to the basal cell layer of the epidermis, which could at times be traced into the epidermis (data not shown). Occasionally epidermal keratinocytes showed diffuse faint immunostaining for IL-12 which was considered as nonspecific as mentioned above for human skin samples.

\section{IL-12 Immunostaining of Human Peripheral and Central Nervous System}

IL-12 immunoreactivity was seen within samples of sural nerve and femoral nerve, and included strong and diffuse staining within the axons (Figs. 3 and 4). In cross-sections, it was obvious that the axons were IL-12 positive, and the surrounding myelin sheath was completely devoid of any staining. However, the Schwann cells cytoplasm was positive for IL-12 (Fig. 4, arrows).

Within dorsal root ganglia, occasional perikaria of the ganglion cells were IL- 12 positive (Fig. 5), whereas other ganglion cells were negative. Satellite cells were diffusely and strongly positive for IL-12 (Figure 5, inset). Similar positive and negative immunostaining results for IL-12 were observed for sympathetic ganglia (data not shown). In the spinal cord, oligodendroglial cells were IL- 12 positive, but no staining of anterior horn motor neurons or astrocyte cells was observed (Fig. 6).

\section{Localization of IL-12 in the Peripheral and Central Nervous System in the Rat}

Staining of rat nervous tissue for IL-12 revealed similar results as for human tissue (data not shown). In addition, in the rat brain, positive IL-12 staining was demonstrated in oligodendroglia cells of the white manner, whereas in the cerebral cortex only occasional large pyramidal cells showed strong immunostaining. Astrocytes in both the spinal cord and brain were negative for IL-12 immunoreactivity.

\section{Detection of IL-12 p35 and p40 mRNAs by RT-PCR}

To assess the source and relative amounts of $\mathrm{p} 40$ mRNA in the neural crest-derived tissues and cultured cell types, semiquantitative RT-PCR was performed. For these studies, resting and activated splenocytes were used as controls. Figure 7 shows a composite RT-PCR result for dilution of splenocyte RNA ranging from 0.25 to $0.0004 \mu \mathrm{g}$ RNA. IL-12 p40 mRNA which was barely detectable in resting splenocytes, increased 50- to 100fold after Con A stimulation (middle panel). Compared with splenocyte levels, the mouse and rat tissues, as well as cultured rat cell of neural origin, produced less IL-12 p40 mRNA (Fig. 7). Among mouse tissues, positive IL-12 p40 mRNA signals were observed for sympathetic ganglion, dorsal root ganglion, and spinal cord. In rat tissues, sympathetic ganglion, sciatic nerve, and

FIG. 1. IL-12 immunoreactivity in normal adult human skin

Within skin, dermal nerve fibers are positive (arrows), and at higher magnification (inset), free nerve endings piercing the epidermal basement membrane zone (arrowhead) contain IL-12 protein.

\section{FIG. 2. Nerve fibers innervating pili erector smooth muscle bundles contain IL-12}

FIG. 3. IL-12 immunoreactivity in large human peripheral nerves

Parallel section of sural nerve reveals almost every axonal process is IL-12 positive (arrows).

FIG. 4. Transverse section of femoral nerve confirms axons, but not surrounding myelin sheaths (blue), are IL-12 positive (bright red)

Also note IL-12-positive Schwann cells (arrows).

FIG. 5. IL-12 immunoreactivity in the human dorsal root ganglia

Occasional gangliocytes are IL-12 positive (arrow), whereas other neuronal nuclei were negative. Satellite cells were diffusely and strongly IL-12 positive (arrows) as highlighted in the inset which palisade around IL-12 negative gangliocytes.

FIG. 6. IL-12 immunoreactivity in human spinal cord showing anterior column white matter with positive IL-12 immunoreactivity of oligodendroglial cells (arrows)

Note negative staining of myelin and axons. 


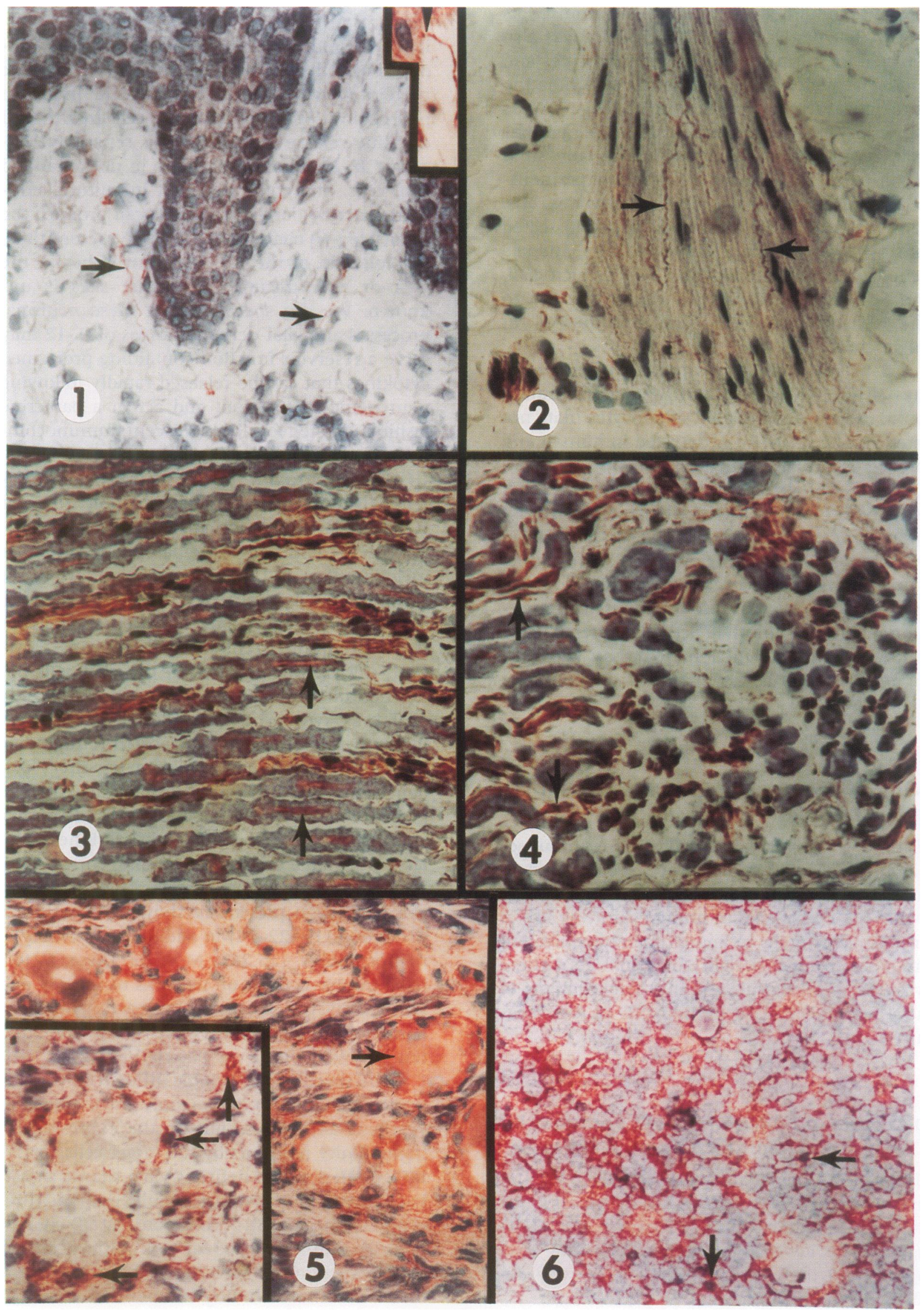


skin all contained detectable p40 transcripts (Fig. 7, left panels). IL-12 p40 mRNA was also detected in cultures of rat oligodendrocytes and microglial which was not due to contaminating astrocytes since these cells were negative for this transcript (Fig. 7, right panel). From the peripheral nervous system, IL-12 p40 mRNA was found in cultures of rat Schwann cells but not perineurial fibroblasts or dorsal root ganglia neurons. IL-12 p40 mRNA isolated from freshly dissected rat sciatic nerves, sciatic nerve explants, and enriched cell cultures (oligodendrocytes, microglial, and Schwann cells) was present at one 5th to one 50th the level found Con A stimulated rat splenocytes.

IL-12 p35 mRNA was present in many tissues at one 5th to one 200th the concentration found in Con A stimulated splenocytes (data not shown). The mRNA was detected in human and mouse tissues including sciatic, sural, sympathetic nerves, dorsal root ganglia, spinal cord, skin, and brain. As the rat sequence is not known, the concentration of IL-12 p35 mRNA in rat tissues could not be determined. Since a functional ELISA to detect rat IL-12 protein does not exist, it was not possible to quantitate the corresponding levels of protein actually secreted using ELISA although a functional bioassay was used for rat Schwann cell conditioned medium (see the last section).

\section{Detection of IL-12 by ELISA in Human Tissue Samples}

Using a sensitive and specific ELISA, homogenates of human tissue extracts were found to contain IL-12. The amount of IL-12 present in 4-mm punch biopsies of human skin was $114 \pm$ $26 \mathrm{ng} / \mathrm{ml}$, whereas in approximately equivalent amounts (by wet weight) of spinal cord there was $266 \pm 49 \mathrm{ng} / \mathrm{ml}$, and in $3-\mathrm{cm}$ segments of sural nerve $899 \pm 78 \mathrm{ng} / \mathrm{ml}$ of IL-12 was measured.

\section{Detection of Functional IL-12 Produced by Cultured Schwann Cells Using A Bioassay}

Using a sensitive bioassay procedure representative bioactivity levels detected in the conditioned medium of rat Schwann cells was $0.23 \pm 0.07$ $\mathrm{ng} / \mathrm{ml}$. The lower limit of detection was 0.01 $\mathrm{ng} / \mathrm{ml}$, and there was no IL-12 bioactivity detected in the medium alone.

\section{DISCUSSION}

IL-12 is predominantly regarded as being produced by activated monocytes as a heterodimeric protein (constitutive p35 chain and inducible p40 chain), which promotes $T$ cell growth and cytokine release $(20,21)$. In this report, we observed IL-12 immunoreactivity in neuronal and glial cells, and confirmed that in culture, nonbone marrow-derived glial cells can produce the inducible p40 chain mRNA. At the present time, the function of the IL-12 present either in the skin or at extracutaneous tissue sites is unknown. We can speculate that these neuronal processes and glial-derived sources of IL-12 may serve a reservoir function containing preformed cytokines that can be released rapidly following neurogenic stimulation, and act in a paracrine fashion targeted locally at adjacent immunocompetent cells.

The distribution pattern of mRNA and protein suggest a possible neurotrophic role for IL-12 similar to that for ciliary neurotrophic factor (CNTF) and related hematopoetic cytokines including IL-6 and lymphocyte inhibitory factor (LIF). IL-12 was localized to neuronal cell bodies and processes, and to myelin-forming glial cells which are in direct contact with neurons. However, mRNA was detected in the glial cells but not neuronal cells in vitro, suggesting that only glial cells synthesize and release IL- 12 which might be taken up and transported retrogradely by neurons. Although we have no direct evidence that IL-12 has neurotrophic activity, the presence of IL-12 in subpopulations of sensory and sympathetic neurons in the periphery and large pyramidal cells in the cerebral cortex mark these cells as potential targets. Myelin-forming glia have been previously shown to synthesize CNTF and LIF (22-24) in addition to a family of neurotrophins $(25,26)$. Most of these factors have trophic activity on neurons in sensory and sympathetic ganglia, and may be acting independently on unique subsets of cells or in combination on overlapping cell populations (27).

The specificity of trophic influence by a particular factor depends not only on the sites of synthesis and release but on the expression of high affinity receptors by the target cells. CNTF, LIF and IL- 6 act on neurons via a shared signaling pathway that involves a multicomponent receptor complex (28). A common $130-\mathrm{kD}$ component (gp130) is required for high-affinity binding dimerization, and signal transduction, while various low-affinity binding components confer li- 


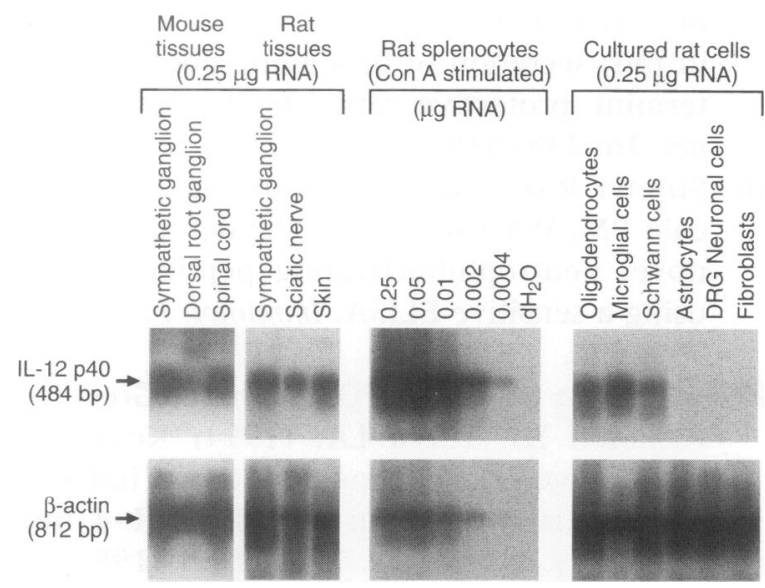

FIG. 7. Composite IL-12 p40 and actin mRNA levels as determined by RT-PCR in mouse and rat tissues (left panel); Con $A$ stimulated rat splenocytes (middle panel); and in cultured rat cells (right panel) (see Materials and Methods for details)

gand specificity. The p40 subunit of IL- 12 resembles the soluble form of the low-affinity receptors for IL- 6 and CNTF, which has led to the concept that IL-12 is produced as a preformed complex between a soluble receptor (p40) and a cytokine (p35). Based on analogy with IL-6/LIF/CNTF, a gp130-like molecule was predicted to form part of the IL- 12 receptor (8). Indeed, a cDNA encoding a molecule with strong homology to gpl30 has recently been cloned (29). However, IL-12 binds to this receptor with low affinity and dimerization appears to be ligand independent. An additional protein has been found in association with the gp130-like IL-12 receptor that could be a subunit required for high-affinity binding and functional activity (30). Identification of the high-affinity converter for IL-12 receptor is crucial for defining target cell populations for IL-12 both within and outside the nervous system.

IL-12, by virtue of its anatomic location in neural tissue, may also participate in immune responses associated with infectious and noninfectious inflammatory disease processes within the nervous system and skin. IL-12 induces the differentiation of $\mathrm{T}$ lymphocytes to $\mathrm{T}$ helper 1 cells which initiates cell-mediated immunity (8). In patients with viral encephalitis or multiple sclerosis, $\mathrm{T}$ cells infiltrate brain tissue and the release of IL- 12 by oligodendrocytes could contribute to the development of immune responses or autoimmune reactions. $\mathrm{CD} 4^{+} \mathrm{T}$-helper-1 clones have been isolated from the cerebrospinal fluid of patients with multiple sclerosis, and activated $\mathrm{CD}^{+} \mathrm{T}$ cells have been shown to secrete factors that induce lysis of oligodendrocytes $(31,32)$. The levels of IL-12 detected in the conditioned medium obtained from the cultured Schwann cells is sufficient to activate a $\mathrm{T}$ cell response either to Mycobacterium avium (33) or bacterial-derived superantigen (17).

In a common $\mathrm{T}$ cell-mediated skin disease such as psoriasis, we have recently demonstrated that the cytokine network present in untreated lesions closely resembles the $\mathrm{T}$ helper type 1 immunological response (8). The present finding that cutaneous nerves contain IL- 12 suggests that neural stimulation might provide a source of IL-12 which is important in generating or maintaining a Th-1 response, and in this way might be able to influence the nature of a local immune response in the skin. Such a pathway would also provide a potential mechanism for the long-described connection between neural influences and psoriasis. However, we would caution that a direct link has not yet been established, and that IL-12 staining patterns were similar in both normal and diseased skin. Nonetheless, our findings that IL-12 is contained within peripheral and central nervous tissue indicate that additional studies are warranted to determine whether targeting neuronal cells and their release of IL-12 will be of therapeutic value in inflammatory/ immune-mediated disorders.

\section{ACKNOWLEDGMENTS}

We thank Stan Wolf (Immunology Department of Genetics Institute, Inc.) for providing recombinant human IL-12 and anti-IL-12 mAbs, and for performing IL-12 bioassays. Keith Bishop (University of Michigan) is acknowledge for primers for mouse IL-12 p35, and J. M. Hopkins and M. Tavakoli-Nezhad for neural cell cultures. Supported in part by National Institutes of Health Grants AR40065, 01823,40488 (BJN); N521700 (JLR); and DK43884 and DK20572 (AAFS).

\section{REFERENCES}

1. Payan D, McGillis J, Goetzl E. (1986) Neuroimmunology. Adv. Immunol. 39: 299-323.

2. Farber EM, Nickoloff BJ, Recht B, Fraki JE. (1986) Stress, symmetry, and psoriasis: Pos- 
sible role of neuropeptides. J. Am. Acad. Dermatol. 14: 305-311.

3. Weihe E, Hartschuh W. (1988) Multiple peptides in cutaneous nerves: Regulators under physiological conditions and a pathogenic role in skin disease. Semin. Dermatol. 7: 284300.

4. Naukkarinen A, Nickoloff BJ, Farber EM. (1989) Quantification of cutaneous nerves and their substance P content in psoriasis. $J$. Invest. Dermatol. 92: 126-129.

5. Hosoi J, Murphy GF, Egan CL, et al. (1993) Regulation of Langerhans cell function by nerves containing calcitonin-gene related peptide. Nature. 363: 159-163.

6. Hsieh CS, Macatonia SE, Tripp CS, Wolf SF, O'Garra A, Murphy KM. (1993) Development of TH-1, CD4+ T cells through IL-12 produced by Listeria-induced macrophages. Science 260: 547-549.

7. Trinchieri G. (1994) Interleukin-12 and its role in the generation of TH-1 cells. Immunol. Today 14: 335-338.

8. Uyemura K, Yamamura M, Fivenson DF, Modlin RL, Nickoloff BJ. (1993) The cytokine network in psoriasis is characterized by a T-helper type 1 cell mediated response. $J$. Invest. Dermatol. 101: 701-705.

9. Brockes JP. (1987) Assay and isolation of glial growth factor from the bovine pituitary. Methods Enzymol. 147: 217-225.

10. Rutkowski L, Needham L, Frayer K, Carson D, McKhann G, Tennekoon GI. (1990) Evidence that secondary rat Schwann cells in culture maintain their differentiated phenotype. J. Neurochem. 54: 1895-1904.

11. Wood P. (1976) Separation and function of Schwann cells and neurons from normal peripheral nerve tissue. Brain Res. 115: 361375.

12. Chomczynski P, Sacchi N. (1987) Single-step method of RNA isolation by acid guanidinium thiocyanate-phenol-chloroform extraction. Anal. Biochem. 162: 156-169.

13. Goodman RE, Oblak J, Bell RG. (1991) Synthesis and characterization of rat interleukin-10 (IL-10) cDNA clones from the RNA of cultured $\mathrm{OX}^{-} \mathrm{OX22}^{-}$thoracic duct $\mathrm{T}$ cells. Biochem. Biophys. Res. Commun. 189: 1-7.

14. Schoenhaut DS, Chua AO, Wolitzky AG, et al. (1991) Cloning and expression of murine IL-12. J. Immunology 148: 3433-3440.

15. Ramaswamy K, Goodman RE, Bell RG. (1994) Cytokine profile of protective antiTrichinella spiralis $\mathrm{CD} 4+\mathrm{OX} 22^{-}$and non- protective CD4+ OX22+ thoracic duct cells in rats: secretion of IL-4 alone does not determine protective capacity. Parasite Immunol. 16: 435-445.

16. Strieter RM, Kunkel SL, Burdick MD, Lincoln PM, Walz A. (1991) The detection of a novel neutrophil-activating peptide (ENA) using a sensitive ELISA. Immunol. Invest. 21: 589-596.

17. Goodman R, Nestle FO, Naidu Y, Green J, Nickoloff BJ, Turka LA. (1994) Keratinocyte-derived T-cell co-stimulation induces preferential production of IL-2 and IL-4, but not IFN- $\gamma$. J. Immunol. 152: 5189-5198.

18. Gately MK, Warrier RR, Honasoge S, Hubbard BR, Murphy BM. (1994) Administration of recombinant IL-12 to normal mice enhances cytolytic monocyte activity and induces production of IFN- $\gamma$ in vivo. Int. Immunol. 1: 157-167.

19. Hori T, Uchiyama T, Tsudo M, et al. (1987) Establishment of an interleukin-2 dependent human $\mathrm{T}$ cell line from a patient with $\mathrm{T}$ cell chronic lymphocytic leukemia who is not infected with human $\mathrm{T}$ cell leukemia/ lymphoma virus. Blood 70: 1069-1072.

20. D'Andrea A, et al. (1991) Production of natural killer cell stimulatory cell factor (interleukin-12) by peripheral blood mononuclear cells. J. Exp. Med. 176: 1387-1394.

21. Gately MK, et al. (1991) Regulation of human lymphocyte proliferation by a heterodimeric cytokine, IL-12 (cytotoxic lymphocyte maturation factor). J. Immunol. 147: 874-882.

22. Dobrea GM, Unnerstall JR, Rao MS. (1991) The expression of CNTF message and immunoreactivity in the central and peripheral nervous system of the rat. Brain. Res. Dev. 66: 209-219.

23. Friedman B, et al. (1991) Regulation of ciliary neurotrophic factor expression in myelin-related Shwann cells in vivo. Neuron 9: 295-305.

24. Curtis R, et al. (1991) Retrograde axonal transport of LIF is increased by peripheral nerve injury: Correlation with increased LIF expression in distal nerve. Neuron 12: 191204.

25. Heumann $R$, Korsching $S$, Thoenen $H$. (1987) Changes of nerve growth factor synthesis in nonneuronal cells in response to sciatic nerve transection. J. Cell. Biol. 104: 1623-1631.

26. Acheson A, Barker PA, Alderson RF, Miller 
FD, Murphy RA. (1991) Detection of brainderived neurotrophic factor-like activity in fibroblasts and Schwann cells: Inhibition by antibodies to NGF. Neuron 7: 265-275.

27. Korsching S. (1993) The neurotrophic factor concept: A reexamination. J. Neurosci. 13: 2739-2748.

28. Stahl N, Boulton TG, Farruggella $\mathrm{T}$, et al. (1994) Association and activation of Jak-Tyk kinases by CNTF-LIF-OSM-IL-6 beta receptor components. Science 263: 92-95.

29. Chua AO, Chizzonite R, DeSai BB, et al. (1994) Expression cloning of a human IL-12 receptor component. A new member of the cytokine receptor superfamily with strong homology to gp130. J. Immunol. 153: 128136.

30. Chizzonite R, Truitt T, Desai BB, et al. (1991)
IL- 12 receptor. I. Characterization of the receptor on phytohemagglutinin-activated human lymphoblasts. J. Immunol. 148: $3117-$ 3124.

31. Benvenuto R, Paroli M, Buttinelli C, Franco A, Fieschi C, Balsano F. (1991) Tumor necrosis factor-alpha and interferon-gamma synthesis by cerebrospinal fluid-derived $\mathrm{T}$ cell clones in multiple sclerosis. Ann. N.Y. Acad. Sci. 650: 341-346.

32. Antel JP, Williams K, Blain M, McRea E, McLaurin J. (1994) Oligodendrocyte lysis by CD4+ T cells independent of tumor necrosis factor. Ann. Neurol. 35: 341-348.

33. Sieling PA, Wang $\mathrm{XH}$, Gately $\mathrm{MK}$, et al. (1994) IL- 12 regulates T helper type 1 cytokine responses in human infectious disease. J. Immunol. 153: 3639-3647.

Contributed by T. Yamada on June 21, 1995. 